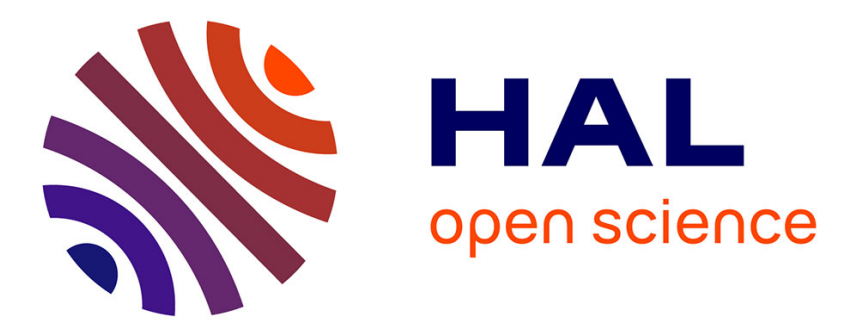

\title{
Molecular characterisation of strains isolated from small and large ruminants reveals a host rather than tissue specificity
}

P.D.D. Alves, J.A. Mcculloch, Sergine Even, C. Le Maréchal, A. Thierry, N. Grosset, V. Azevedo, C.A. Rosa, E. Vautor, Yves Le Loir

\section{To cite this version:}

P.D.D. Alves, J.A. Mcculloch, Sergine Even, C. Le Maréchal, A. Thierry, et al.. Molecular characterisation of strains isolated from small and large ruminants reveals a host rather than tissue specificity. Veterinary Microbiology, 2009, 137 (1-2), pp.190. 10.1016/j.vetmic.2008.12.014 . hal-00485522

\section{HAL Id: hal-00485522 \\ https://hal.science/hal-00485522}

Submitted on 21 May 2010

HAL is a multi-disciplinary open access archive for the deposit and dissemination of scientific research documents, whether they are published or not. The documents may come from teaching and research institutions in France or abroad, or from public or private research centers.
L'archive ouverte pluridisciplinaire HAL, est destinée au dépôt et à la diffusion de documents scientifiques de niveau recherche, publiés ou non, émanant des établissements d'enseignement et de recherche français ou étrangers, des laboratoires publics ou privés. 


\section{Accepted Manuscript}

Title: Molecular characterisation of Staphylcoccus aureus strains isolated from small and large ruminants reveals a host rather than tissue specificity

Authors: P.D.D. Alves, J.A. McCulloch, S. Even, C. Le Maréchal, A. Thierry, N. Grosset, V. Azevedo, C.A. Rosa, E.

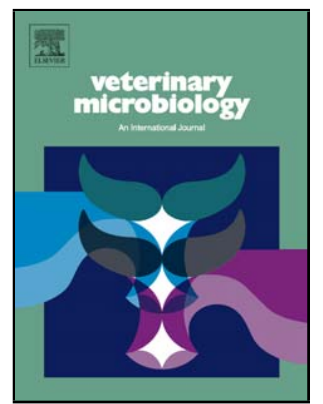
Vautor, Y. Le Loir $<$ ce:footnote id="fn1" $><$ ce:note-para $>$ Equal contribution. $</$ ce:note-para $></$ ce:footnote $>$

PII: $\quad$ S0378-1135(08)00585-3

DOI: $\quad$ doi:10.1016/j.vetmic.2008.12.014

Reference: $\quad$ VETMIC 4303

To appear in: $\quad$ VETMIC

Received date: $\quad 23-10-2008$

Revised date: $\quad 10-12-2008$

Accepted date: $\quad 12-12-2008$

Please cite this article as: Alves, P.D.D., McCulloch, J.A., Even, S., Le Maréchal, C., Thierry, A., Grosset, N., Azevedo, V., Rosa, C.A., Vautor, E., Le Loir, Y., Molecular characterisation of Staphylcoccus aureus strains isolated from small and large ruminants reveals a host rather than tissue specificity, Veterinary Microbiology (2008), doi:10.1016/j.vetmic.2008.12.014

This is a PDF file of an unedited manuscript that has been accepted for publication. As a service to our customers we are providing this early version of the manuscript. The manuscript will undergo copyediting, typesetting, and review of the resulting proof before it is published in its final form. Please note that during the production process errors may be discovered which could affect the content, and all legal disclaimers that apply to the journal pertain. 
4 Molecular characterisation of Staphylcoccus aureus strains isolated from small and large 5 ruminants reveals a host rather than tissue specificity

6

7

8

P. D. D. Alves ${ }^{1,2,3 \S}$, J. A. McCulloch ${ }^{1,2 \S}$, S. Even ${ }^{1,2}$, C. Le Maréchal ${ }^{1,2}$, A. Thierry ${ }^{1,2}$, N.

9 Grosset $^{1,2}$, V. Azevedo ${ }^{3}$, C. A. Rosa ${ }^{3}$, E. Vautor ${ }^{4}$ and Y. Le Loir ${ }^{1,2} *$

10

11

12

13

(1) INRA, UMR1253 STLO, 85 rue de Saint Brieuc, 35042 Rennes, France;

14

(2) Agrocampus Ouest, UMR1253 STLO, 85 rue de Saint Brieuc, 35042 Rennes, France;

15

(3) Instituto de Ciências Biológicas, Universidade Federal de Minas Gerais, Brazil;

16

(4) PPR, AFSSA Sophia Antipolis, France

17

18

19 §: equal contribution

$20 *$ : corresponding author

21 yves.leloir@rennes.inra.fr

22 


\section{Abstract}

Staphylococcus aureus is an important pathogen in domestic ruminants. The main objective of this study was to determine the similarity of epidemiologically unrelated $S$. aureus isolates from bovine, ovine, and caprine hosts regardless the locus of isolation (nares and udder). By pulsed-field gel electrophoresis, 7 major pulsotypes were identified among 153 isolates recovered from 12 different regions of France as well as from Brazil, the USA and Belgium.

30 Typing of the accessory gene regulator ( $a g r)$ and capsular (cap) serotype was carried out on 31 all the isolates and revealed the predominance of agrI and III and of cap 8 regardless the ruminant host species. Screening for MRSA was carried out by disk diffusion and revealed a prevalence of only $3.2 \%$ of MRSA among the strains tested. These results suggest the existence of a host rather than tissue specificity among $S$. aureus isolates colonising the ruminant species and suggest a limited transmission of those isolates between large (bovine) and small (ovine-caprine) ruminants. The agr class and cap types correlated with pulsotype clusters rather than with a specific host species. Antimicrobial resistance appears not to have contributed to the predominance of any given genotypes, and MRSA prevalence appears very

39 low in ruminant isolates.

40

Keywords: Staphylococcus aureus, Ruminant, host specificity, mastitis, PFGE 


\section{Introduction}

$S$. aureus is one of the most frequent etiologic agents of mastitis in bovines, ovines and caprines, rendering livestock unable to adequately produce milk, which results in heavy economic losses for the dairy industry (Seegers et al., 2003). Studies characterising ruminant isolates of $S$. aureus are scarce compared to the much more abundant data on human isolates. Devriese et al. first described phenotypic differences between $S$. aureus strains isolated from humans and other animal hosts including bovines and ovines, and proposed a scheme for the distinction of several host biotypes (Devriese and Oeding, 1976). Differences between host biotypes are also reflected at the genotypic level as determined by macro-restriction analysis of the chromosome (Hennekinne et al., 2003). Due to the specificity of host-pathogen interactions needed to produce mastitis, it has been postulated that the nature of the virulon and the regulation of its expression are determining factors when it comes to the ability of a strain to produce mastitis (Vautor et al., 2008). The recent release of the complete genome sequence of $S$. aureus ET-3, a bovine isolate, provides new insight into the genomic basis of a putative host adaptation and the existence of host specific genetic traits in $S$. aureus isolated from bovine hosts (Herron-Olson et al., 2007). We recently showed that diversification of the S. aureus core genome correlated with host origin in ruminants (Ben Zakour et al., 2008). However, in most studies, the panel of ruminant $S$. aureus strains comprised mostly strains isolated from cases of mastitis. The mammary gland tissues present characteristics such that some authors hypothesized that the specific traits found to be common in bovine strains were related to a tissue- rather than to host- specificity (van Leeuwen et al., 2005). In the present study, we characterised several $S$. aureus isolates obtained from different sites of colonisation / infection, from ruminants in different geographic regions, by PFGE, and further characterised the strains as to their agr group and capsular polysaccharide genotype. The aims of this characterisation were to verify whether the strains groups reflected a host- or tissue- 
adaptation, whether there is a predisposition of certain cap or agr types to colonise or infect certain ruminant hosts.

\section{Material and Methods}

\subsection{Bacterial strains.}

In order to minimise bias when evaluating clonality by PFGE, we chose to include in the study strains from different geographic and temporal backgrounds. A total of $153 \mathrm{~S}$. aureus isolates were either chosen from existing collections $(n=114)$ or were collected specifically for this study ( $\mathrm{n}=39$ ). Isolates from bovine (65 strains), ovine (57), and caprine (31) hosts were collected between 1964 and 2006 in France (12 different regions, n=117), and Brazil (2 different regions, $n=30)$. The panel of strains included also isolates from Belgium $(n=5)$ and the USA ( $\mathrm{n}=1)$. Strains chosen from existing collections were confirmed to be $S$. aureus by a specific PCR test (Baron et al., 2004). The strains collected in this study were isolated from the udder (mastitic milk) and nares of bovine, ovine, and caprine hosts as described previously (Vautor et al., 2003). Samples were first grown on selective Baird-Parker medium. Species identification was carried out on coagulase positive staphylococci using previously described PCR tests (Baron et al., 2004; Morot-Bizot et al., 2004). Details of the sampling used in this study (locus of isolation and host) are given in Table 1.

2.2. PFGE. Pulsed-Field Gel Electrophoresis for the characterisation of the strain lineage was carried out according to previously described protocols (Prevost et al., 1992b). The band profiles obtained for each strain were analysed using the Bionumerics software, version 2.0 (Applied-Maths, Belgium).

2.3. Determination of the agr group. Classification of strains into agr interference groups was carried out by PCR according to Gilot et al. (Gilot and van Leeuwen, 2004), which 
involves a forward primer common to all agr groups and four primers, each one specific to each agr group.

2.4. Determination of the capsular polysaccharide type. The capsular polysaccharide type was determined by means of PCR with primers directed to sequences of the staphylococcal capsular polysaccharide gene (cap) specific to either the type 5 (primers Cap5k1 and Cap5k2) or type 8 (primers Cap8k1 and Cap8k2) alleles, as described by Verdier et al. (Verdier et al., 2007). Each strain was submitted to a reaction using either the Cap5k1 and Cap5k2 or the Cap8k1 and Cap8k2 primer pair in independent reactions.

2.5. Determination of the susceptibility of strains to oxacillin. Susceptibilities of strains to oxacillin were evaluated by means of the Kirby-Bauer disk diffusion method as described previously (CLSI, 2007).

\subsection{Statistical analyses.}

A $\chi^{2}$ test was used to determine the significance of occurrence of genes in a host specific group by use of Statgraphics version 5.1. The nominal P value for statistical significance was 0.05

\section{Results and discussion}

\subsection{S. aureus strains grouped with regard to their host- but not tissue- origin.} Macrorestriction profile analysis using PFGE is one of the most discriminative methods for $S$. aureus when compared to other genotyping methods (Kuhn et al., 2007; Prevost et al., 1992a; van Belkum et al., 1994). All the strains studied here grouped up into 7 clusters (A to $\mathrm{G}-$ figure 1) when analyzed by PFGE considering a similarity cut-off of $48 \%$. Each cluster was significantly correlated $(\mathrm{P}<0.05)$ to the subfamily of the host (bovine for large ruminants or 
ovine-caprine for small ruminants) from which the strains were isolated. Three clusters were

121 majorly composed of bovine isolates: 42 out of 45 strains (93\%) are bovine isolates in cluster B; $7 / 10$ strains $(70 \%)$ in cluster $\mathrm{C}$; and $7 / 13$ strains $(54 \%)$ in cluster $\mathrm{E}$. The four other clusters comprised a great majority of small ruminants isolates: 24 out of 24 strains $(100 \%)$

124 are ovine-caprine isolates in cluster A; 43/49 strains (88\%) in cluster D; 7/9 strains (78 \%) in 125 cluster F; and 3/3 strains (100\%) in cluster G. Strains isolated from small ruminants could not

126 be distinguished as to whether they were ovine or caprine based on their pulsotype, as they were evenly distributed along clusters A, D, F, and G. Strains isolated from ovine and caprine hosts presented a similarity of up to $100 \%$, whereas no bovine strain presented a $100 \%$ similarity to a small ruminant strain. Previous studies based on CGH analysis of S. aureus

130 isolates including a few bovine strains suggested the existence of tissue- rather than host131 specific genetic traits (van Leeuwen et al., 2005). However, in these studies, only a few bovine mastitis isolates were analyzed amongst a large panel of human strains. Our results are in contrast to another work showing that there is little or no host preference among S. aureus

134 presenting different genotypes (Mork et al., 2005), in which isolates were obtained from milk 135 collected from cases of clinical and subclinical mastitis in ewes kept for meat production. In 136 the present study, we included strains isolated from the nares and udder of various ruminant 137 hosts and results showed that they were evenly distributed amongst each of the clusters

138 (Figure 1). Thus S. aureus strains clearly grouped up into clusters which correlated to the type 139 of host they were isolated from. In contrast, there was no significant correlation between 140 clusters and the locus of isolation, geographic origin or date of isolation, as strains from the 141 same geographic origin and similar dates of isolation were found to be spread among different

142 clusters. Our results are in accordance with previous studies which reported that host 143 biotypes, as determined according to Devriese's scheme, are reflected by PFGE profiles 144 (Hennekinne et al., 2003). A recent study by Sung et al. (Sung et al., 2008) which evaluated 145 the relatedness of strains of human and non-human (ruminants and equines) origin also found 
146 that bovine strains tend to cluster into a few specific clonal clusters, which are different to

147 predominantly human clusters. In this study, small ruminant strains were grouped into a

148 bovine and equine cluster (ST771), however, the limited number of small ruminant strains

149 analysed $(n=4)$ make it impossible to conclude on the specificity of small ruminant strains.

150 Lineages might be adapted to colonise a certain type of host independent of the site of

151 colonisation/infection. The fact that there was significant correlation between the sub-family

152 of the animal host and lineage, in spite of the strains having been isolated from very different 153 geographical locations (all major regions of France, plus isolates from Brazil, Belgium, and

154 the USA) and in different years (from 1964 to 2006), strongly indicates that a certain strain

155 has a penchant for the type of host it is successful in living on. Our study is as of yet the most

156 comprehensive study involving strains isolated from small ruminants. It is important to realise

157 that bovine strains are different to ovine and caprine strains, for this must bear an impact on

158 the adoption of strategies for the prevention of mastitis in small or large ruminants.

159 3.2. Determination of agr group. The ability of $S$. aureus, as a species, to endure in different

160 niches, playing different roles in the relationship with an animal host is testament to either the

161 regulation of the expression of a panoply of accessory genes, or a variability of strains within

162 the species, with lineages presenting a collection of genes specializing in a particular modus 163 vivendi (Ben Zakour et al., 2008; Fitzgerald and Musser, 2001). The expression of the

164 accessory genes in $S$. aureus is under the control of a series of systems that interact with each

165 other to form a network. Of all these systems, the accessory gene regulator (agr), a two-

166 component quorum-sensing system has arguably been the most studied in $S$. aureus. Four

167 interference classes related to genetic polymorphisms in the agr locus have thus far been

168 described, namely, agr groups I, II, III and IV (Jarraud et al., 2002a; Ji et al., 1995). So far,

$169 a g r$ variability has been only rarely studied in isolates obtained from ruminants (Gilot and van

170 Leeuwen, 2004; Reinoso et al., 2008; Vautor et al., 2008). 
171 In this study, altogether, the most prevalent $\operatorname{agr}$ group found was $\operatorname{agr} \mathrm{I}(\mathrm{n}=91,59.5 \%)$,

172 followed by $\operatorname{agr}$ III $(\mathrm{n}=40,26.1 \%)$ and $\operatorname{agr}$ II $(\mathrm{n}=21,13.7 \%)$. Only a single strain bearing an

173

174 agr IV polymorphism was found $(0.6 \%)$ and corresponded to a bovine isolate. If stratified by host type (small or large ruminant), within bovines, the prevalence of agr groups I, II, III and IV were $54.7 \%, 17.2 \%, 26.6 \%$ and $1.6 \%$, respectively, whereas within small ruminants, their prevalence was $62.9 \%, 11.2 \%, 25.8 \%$ and $0 \%$. The ratios of the prevalences of each agr group are approximately the same when considering only small or only large ruminants. This suggests that agr type does not play a role in host specificity. When considering discrete genotype clusters, it appears that, for a given host, some genotypes have a high prevalence of $\operatorname{agr}$ I whereas for some others $a g r$ III is clearly prevalent. It has been previously shown that $S$. aureus strains belonging to agr group I have a greater ability of invading epithelial cells and persist in the mammary gland, respectively, suggesting that they are better at causing clinical or subclinical mastitis than strains of other agr groups (Buzzola et al., 2007). Indeed, this same study found a disproportionately high prevalence (88\%) of agr type I strains causing mastitis in bovines. Our study shows that agr group distribution among ruminant isolates correlated with genotype cluster rather than with a given host. Of note, the distribution of $a g r$ groups was tissue-independent since isolates from mastitis milk, udder skin or nares were found in each cluster. This observation is in agreement with Jarraud et al. (Jarraud et al., 2002b), who demonstrated a relationship between the genetic background of the strains and the $a g r$ allele group. We previously reported the prevalence of agr III ( $46 \%$ vs $44 \%$ for $a g r$ I) in small ruminant isolates and a correlation between geographical region and predominance of a given agr group was hypothesized to explain predominance in some lineages (Vautor et al., 2008). Here, strains originating from various geographical regions grouped within the same clusters and belonged to the same agr group. This suggests that the link between agr allele groups and a given region is likely due to the predominance of a given lineage within the region considered. 
198 3.3. Determination of the capsular polysaccharide type. The cap operon responsible for the 199 biosynthesis of capsular polysaccharides (CP) expressed on the surface of S. aureus belongs to the virulon (O'Riordan and Lee, 2004). There are 11 serotypes of $\mathrm{CP}$, however, the majority of strains isolated from humans express either CP type 5 or type 8 , for which PCR a test has been developed (O'Riordan and Lee, 2004; Verdier et al., 2007). In contrast, a variable prevalence of different CP types has been observed in strains isolated from ruminants from geographically different regions of the world (Guidry et al., 1997; Poutrel et al., 1988; Sordelli et al., 2000) and the actual role of CP in mastitis is questioned (Tuchscherr et al., 2005). Here, strains were CP typed using a PCR test enabling differentiation between CP type 5 and 8 . The prevalence of the types of CP $(5,8$ or non-typeable) for each lineage can be seen in Figure 1. Altogether, the capsular type 8 was predominant in this study and accounted for $65.4 \%$ of the panel. CP type 5 and the non-typeable CP types accounted for $30.7 \%$ and 3.9 $\%$ respectively. When considering the host species, CP type 8 was clearly predominant in small ruminants, with an overall prevalence of $83.1 \%$ in ovine-caprine isolates. In contrast, CP type 5 was slightly predominant in bovine isolates $(56.3 \%)$ and the prevalence of one type over the other seemed dependent of the genotype cluster. The bovine clusters B and C were indeed majorly CP type 5 . These results are in accordance with previous studies on CP typing of $S$. aureus mastitis isolates showing that most bovine isolates were CP type 5 whereas ovine and caprine isolates were CP type 8 (Guidry et al., 1997; Poutrel et al., 1988). The low prevalence of non-typeable strains in this study contrasted with previous work where 218 up to $76.5 \%$ of bovine mastitis strains (Sompolinsky et al., 1985) were found to be nontypeable. However, in this latter study only 17 strains were typed and the geographical region of isolation is not mentioned although this criterion, as shown above, is of great importance and may, in this case, bias the results. 


\subsection{MRSA screening.}

MRSA strains present a are much more clonal distribution than MSSA (Enright et al., 2002).

Thus, our initial worry was that if we had a high prevalence of MRSA amongst our strains, this might pose a bias to our results, for MRSA strains would tend to cluster up. Nevertheless, only 5 strains $(3.2 \%$; 3 bovine strains and 2 caprine strains; dispatched in 5 different PFGE clusters) presented resistance to oxacillin, an antibiotic used for the detection of Methicilin Resistant S. aureus (MRSA). Our findings contrast with recent studies in which MRSA was found in the nares of $39 \%$ and $10.9 \%$ of pigs and horses tested, respectively (de Neeling et al., 2007; Van den Eede A. et al., 2008). Together with other studies (Juhasz-Kaszanyitzky et al., 2007), our results confirmed that MRSA prevalence is still low in ruminants.

\section{Conclusions}

S. aureus strains are phenotypically and genomically variable. Pulsotyping of ruminant isolates showed that $S$. aureus strains clustered with regard to their host origin (bovine and ovine-caprine) and regardless the locus of colonization or infection. Accessory gene regulator polymorphism and the type (or presence) of capsular polysaccharide are facets of strain-tostrain difference. The prevalence of each agr group and cap type within each lineage varied with the lineage, however, when analysed within the context of each sub-family of host (small or large ruminant), the prevalences of each agr group or cap type are about the same either in bovines, or ovines/caprines. This hints at the hypothesis that adaptation to a host is not a result of the regulation of a set of accessory genes, but rather the presence/absence or allelic variation of certain genes. The fact that stains found in small ruminants are different from those found in bovines is important enough to warrant the research and development of different immunoprophylactic products against mastitis in small and large ruminants. The low prevalence of resistance to antibiotics found in ruminants suggests that domesticated livestock is not a reservoir of genes which provide resistance to antimicrobial drugs. 
In conclusion, this study shows that the nature of $S$. aureus strains differs between large and

small ruminants and suggests the existence of a host rather than tissue specificity. Further

studies are being pursued for the determination of the molecular nature of this host specificity

and strategies for mastitis prevention in small or large ruminants should take account of these

differences.

\section{Acknowledgements.}

Authors are very grateful to Pascal Pachot (Agrocampus Ouest, France) for advice on

statistical analyses and to Germana K. Chassa (UFMG, Brazil) for support and constructive

discussions all along this work. Priscila D. Alves and John A. McCulloch are the recipients of

a CAPES grant from the Brazilian government (CAPES-COFECUB project 539/06). Caroline

Le Maréchal is the recipient of a PhD grant from INRA and AFSSA (IMISa project).

Reference List

Baron, F., M. F. Cochet, J. L. Pellerin, N. Ben Zakour, A. Lebon, A. Navarro, I. Proudy, Y. Le Loir, and M. Gautier. 2004. Development of a PCR test to differentiate between Staphylococcus aureus and Staphylococcus intermedius. J. Food Prot. 67(10):23022305.

Ben Zakour, N. L., D. E. Sturdevant, S. Even, C. M. Guinane, C. Barbey, P. D. Alves, M. F. Cochet, M. Gautier, M. Otto, J. R. Fitzgerald, and Y. Le Loir. 2008. Genome-wide analysis of ruminant Staphylococcus aureus reveals diversification of the core genome. J. Bacteriol. 190(19):6302-6317.

Buzzola, F. R., L. P. Alvarez, L. P. Tuchscherr, M. S. Barbagelata, S. M. Lattar, L. Calvinho, and D. O. Sordelli. 2007. Differential abilities of capsulated and noncapsulated Staphylococcus aureus isolates from diverse agr groups to invade mammary epithelial cells. Infect. Immun. 75(2):886-891.

de Neeling, A. J., M. J. van den Broek, E. C. Spalburg, M. G. van Santen-Verheuvel, W. D. Dam-Deisz, H. C. Boshuizen, A. W. van de Giessen, D. E. van, and X. W. Huijsdens. 2007. High prevalence of methicillin resistant Staphylococcus aureus in pigs. Vet. Microbiol. 122(3-4):366-372.

Devriese, L. A., and P. Oeding. 1976. Characteristics of Staphylococcus aureus strains isolated from different animal species. Res Vet Sci 21(3):284-91.

Enright, M. C., D. A. Robinson, G. Randle, E. J. Feil, H. Grundmann, and B. G. Spratt. 2002. The evolutionary history of methicillin-resistant Staphylococcus aureus (MRSA). Proc Natl Acad Sci U S A 99(11):7687-92.

Fitzgerald, J. R., and J. M. Musser. 2001. Evolutionary genomics of pathogenic bacteria. Trends Microbiol 9(11):547-53. 
Gilot, P., and W. van Leeuwen. 2004. Comparative analysis of agr locus diversification and overall genetic variability among bovine and human Staphylococcus aureus isolates. J Clin Microbiol 42(3):1265-9.

Guidry, A., A. Fattom, A. Patel, and C. O'Brien. 1997. Prevalence of capsular serotypes among Staphylococcus aureus isolates from cows with mastitis in the United States. Vet. Microbiol. 59(1):53-58.

Hennekinne, J. A., A. Kerouanton, A. Brisabois, and M. L. De Buyser. 2003. Discrimination of Staphylococcus aureus biotypes by pulsed-field gel electrophoresis of DNA macrorestriction fragments. J Appl Microbiol 94(2):321-9.

Herron-Olson, L., J. R. Fitzgerald, J. M. Musser, and V. Kapur. 2007. Molecular Correlates of Host Specialization in Staphylococcus aureus. PLoS ONE 2(10):e1120.

Jarraud, S., C. Mougel, J. Thioulouse, G. Lina, H. Meugnier, F. Forey, X. Nesme, J. Etienne, and F. Vandenesch. 2002b. Relationships between Staphylococcus aureus genetic background, virulence factors, agr groups (alleles), and human disease. Infect. Immun. 70(2):631-641.

Jarraud, S., C. Mougel, J. Thioulouse, G. Lina, H. Meugnier, F. Forey, X. Nesme, J. Etienne, and F. Vandenesch. 2002a. Relationships between Staphylococcus aureus genetic background, virulence factors, agr groups (alleles), and human disease. Infect Immun 70(2):631-41.

Ji, G., R. Beavis, and R. Novick. 1995. Cell Density Control of Staphylococcal Virulence Mediated by an Pheromone 10.1073/pnas.92.26.12055. PNAS 92(26):12055-12059.

Juhasz-Kaszanyitzky, E., S. Janosi, P. Somogyi, A. Dan, van der Graaf-van Bloois, D. E. van, and J. A. Wagenaar. 2007. MRSA transmission between cows and humans. Emerg. Infect. Dis. 13(4):630-632.

Kuhn, G., P. Francioli, and D. S. Blanc. 2007. Double-locus sequence typing using clfB and spa, a fast and simple method for epidemiological typing of methicillin-resistant Staphylococcus aureus. J. Clin. Microbiol. 45(1):54-62.

Mork, T., T. Tollersrud, B. Kvitle, H. J. Jorgensen, and S. Waage. 2005. Comparison of Staphylococcus aureus genotypes recovered from cases of bovine, ovine, and caprine mastitis. J Clin Microbiol 43(8):3979-84.

Morot-Bizot, S. C., R. Talon, and S. Leroy. 2004. Development of a multiplex PCR for the identification of Staphylococcus genus and four staphylococcal species isolated from food. J. Appl. Microbiol. 97(5):1087-1094.

O'Riordan, K., and J. C. Lee. 2004. Staphylococcus aureus capsular polysaccharides. Clin. Microbiol. Rev. 17(1):218-234.

Poutrel, B., A. Boutonnier, L. Sutra, and J. M. Fournier. 1988. Prevalence of capsular polysaccharide types 5 and 8 among Staphylococcus aureus isolates from cow, goat, and ewe milk. J. Clin. Microbiol. 26(1):38-40.

Prevost, G., B. Jaulhac, and Y. Piemont. 1992a. DNA Fingerprinting by Pulsed-Field Gel Electrophoresis Is More Effective than Ribotyping in Distinguishing among Methicillin- Resistant Staphylococcus aureus Isolates. J. Clin. Microbiol. 30:967-973.

Prevost, G., B. Jaulhac, and Y. Piemont. 1992b. DNA fingerprinting by pulsed-field gel electrophoresis is more effective than ribotyping in distinguishing among methicillinresistant Staphylococcus aureus isolates. J. Clin. Microbiol. 30(4):967-973.

Reinoso, E. B., A. El-Sayed, C. Lammler, C. Bogni, and M. Zschock. 2008. Genotyping of Staphylococcus aureus isolated from humans, bovine subclinical mastitis and food samples in Argentina. Microbiol. Res. 163(3):314-322.

Seegers, H., C. Fourichon, and F. Beaudeau. 2003. Production effects related to mastitis and mastitis economics in dairy cattle herds. Vet Res 34(5):475-91. 
Sompolinsky, D., Z. Samra, W. W. Karakawa, W. F. Vann, R. Schneerson, and Z. Malik. 1985. Encapsulation and capsular types in isolates of Staphylococcus aureus from different sources and relationship to phage types. J. Clin. Microbiol. 22(5):828-834.

Sordelli, D. O., F. R. Buzzola, M. I. Gomez, L. Steele-Moore, D. Berg, E. Gentilini, M. Catalano, A. J. Reitz, T. Tollersrud, G. Denamiel, P. Jeric, and J. C. Lee. 2000. Capsule expression by bovine isolates of Staphylococcus aureus from Argentina: genetic and epidemiologic analyses. J. Clin. Microbiol. 38(2):846-850.

Sung, J. M., D. H. Lloyd, and J. A. Lindsay. 2008. Staphylococcus aureus host specificity: comparative genomics of human versus animal isolates by multi-strain microarray. Microbiology 154(Pt 7):1949-1959.

Tuchscherr, L. P., F. R. Buzzola, L. P. Alvarez, R. L. Caccuri, J. C. Lee, and D. O. Sordelli. 2005. Capsule-negative Staphylococcus aureus induces chronic experimental mastitis in mice. Infect. Immun. 73(12):7932-7937.

van Belkum, A., R. Bax, and G. Prevost. 1994. Comparison of Four Genotyping Assays for Epidemiological Study of Methicillin-Resistant Staphylococcus aureus. Eur. J. Clin. Microbiol. Infect. Dis. 13:420-424.

Van den Eede A., A. Martens, U. Lipinska, M. Struelens, A. Deplano, O. Denis, F. Haesebrouck, F. Gasthuys, and K. Hermans. 2008. High occurrence of methicillinresistant Staphylococcus aureus ST398 in equine nasal samples. Vet Microbiol.

van Leeuwen, W. B., D. C. Melles, A. Alaidan, M. Al-Ahdal, H. A. Boelens, S. V. Snijders, H. Wertheim, D. E. van, J. K. Peeters, P. J. van der Spek, R. Gorkink, G. Simons, H. A. Verbrugh, and B. A. van. 2005. Host- and tissue-specific pathogenic traits of Staphylococcus aureus. J. Bacteriol. 187(13):4584-4591.

Vautor, E., G. Abadie, J. M. Guibert, C. Huard, and M. Pepin. 2003. Genotyping of Staphylococcus aureus isolated from various sites on farms with dairy sheep using pulsed-field gel electrophoresis. Vet Microbiol 96(1):69-79.

Vautor, E., V. Magnone, G. Rios, B. K. Le, D. Bergonier, G. Lina, H. Meugnier, P. Barbry, R. Thiery, and M. Pepin. 2008. Genetic differences among Staphylococcus aureus isolates from dairy ruminant species: A single-dye DNA microarray approach. Vet. Microbiol.

Verdier, I., G. Durand, M. Bes, K. L. Taylor, G. Lina, F. Vandenesch, A. I. Fattom, and J. Etienne. 2007. Identification of the capsular polysaccharides in Staphylococcus aureus clinical isolates by PCR and agglutination tests. J. Clin. Microbiol. 45(3):725-729. 
372 Table $1-$ S. aureus isolates used in this study.

Sample site No. of isolates

\begin{tabular}{cccc}
\cline { 2 - 4 } & Bovine & Caprine & Ovine \\
\hline nares & 14 & 5 & 39 \\
udder & 51 & 26 & 18 \\
\hline Total & 65 & 31 & 57
\end{tabular}

373

374 


\section{Figure Legend}

Figure 1. PFGE genotyping of the $153 \mathrm{~S}$. aureus strains isolated from ruminants and

identification of their agr, cap group. I, Dendrogram depicting the PFGE macrorestriction

379 analysis of the chromosome and presenting the percentage of genetic similarity between the

380153 strains. The unweighted-pair group method using average linkages and a Dice coefficient

381 (with a tolerance limit of 1\%) were used to build the dendrogram. A dashed line indicates the

382 cut-off value ( $48 \%$ ) chosen to determine the 7 clusters indicated A to G. II, Host of origin of

383 the strains (black, bovine isolates; white, small ruminant isolates). III, site of isolation of the

384 strains belonging to each of the 7 PFGE clusters identified (light grey, nares; dark grey,

385 udder). IV, distribution of agr groups within each of the 7 PFGE clusters (white, agr I, light

386 grey, agr II, dark grey, agr III, black, agr IV). V, distribution of cap groups in the 7 clusters

387 (light grey, cap5, dark grey, cap8; white, non-typeable). The last row gives the overall

388 proportions for site of isolation, agr and cap groups within the entire panel of strains. 


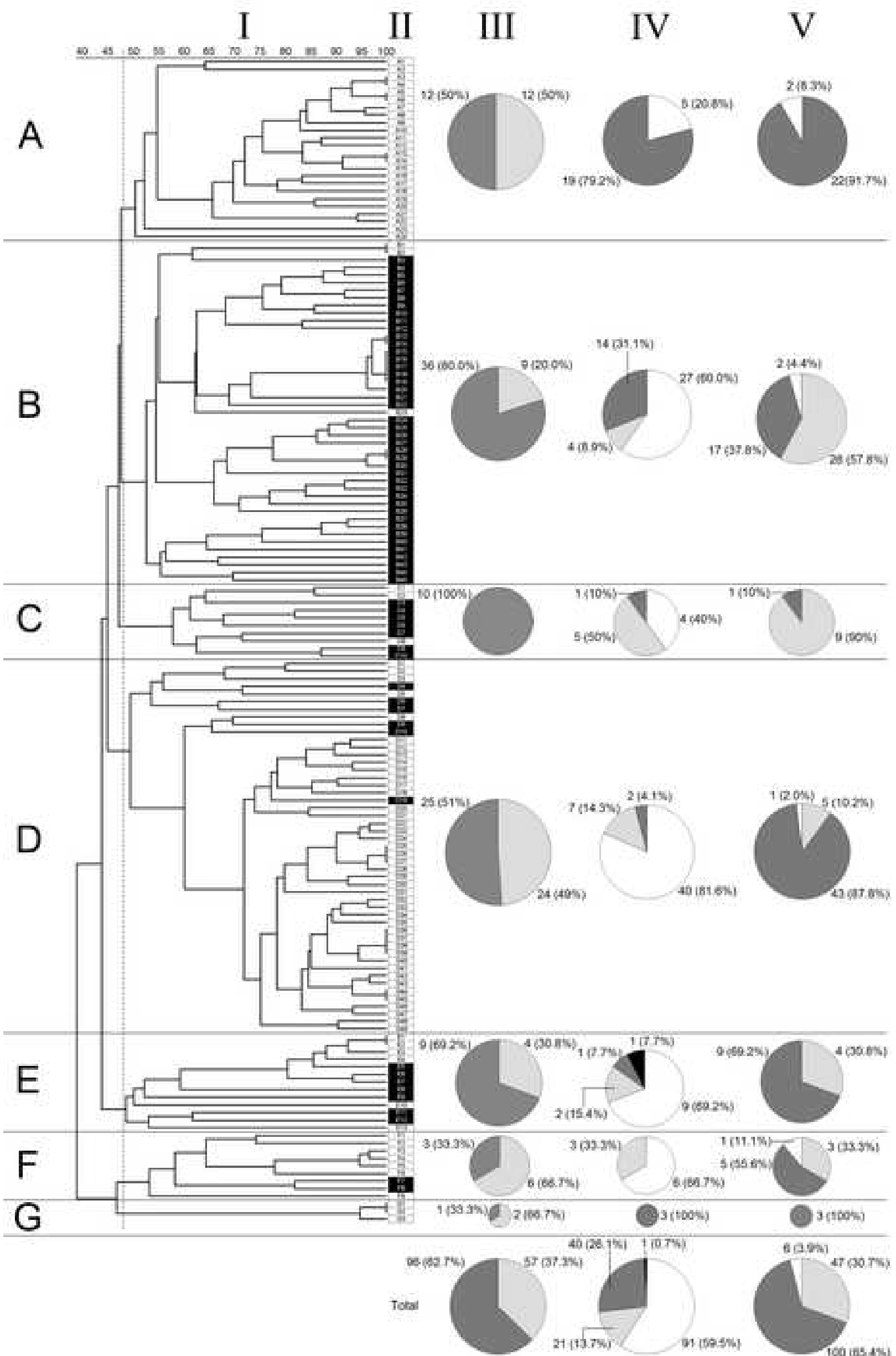

